\title{
Loss of Aggressiveness of Phytophthora cinnamomi (Beta-Cinnamomin Silenced Strain) in the Infection of Castanea sativa
}

\author{
I. Maia*, M. Horta**, A. Cravador** and C. Medeira* \\ * INRB/INIA, Av. da República, Quinta do Marquês 2784-505 Oeiras, Portugal \\ ** IBB/CGB-Universidade da Algarve, FCT, Campus de Gambelas, 8005-139 FARO, Portugal
}

Several forest species are severely affected by Phytophthora cinnamomi. The contribution of this oomycete to forest decline and dieback has been broadly reported. In particular, it is consensual that it is the causal agent of ink disease in Castanea sativa. It has been associated with the severe decline of Quercus species, namely the $Q$. suber and Q. ilex dieback in Portugal and Spain, and has been responsible for the infection of numerous native species and crops. This pathogen persists in the soil or on plant material in the form of chlamydospores allowing the infection of living root tissues when environmental conditions are favorable.

P. cinnamomi secrets cinnamomins, proteins from the elicitin family that appear to be involved in pathogen-host interaction. We have recently reported that the pathogenecity of $P$. cinnamomi was associated with the production of beta-cinnamomin acting as an aggressiveness factor in $Q$. suber infection. The silencing of the beta-cinnamomin gene drastically reduced the colonization of the seedling roots of $Q$. suber in direct contact with $P$. cinnamomi [1].

The objective of the present work is to study, at the cellular level, the interactions: transgenic betacinnamomin knock-down P. cinnamomi strain (FATSS) - C. sativa and P. cinnamomi wild type strain (PA 45) - C. sativa, in order to get insights on the role of elicitins in this infection process.

The roots were inoculated and prepared for microscopy as previously described [1]. All the inoculated roots were rapidly invaded by the wild type strain. The cortical parenchyma was inter and intracellularly colonized (Figure 1A), with the vascular cylinder invaded with severe destruction of the phloem (Figure 1B) and heavy colonization of xylem vessels (Figure 1C) two days after inoculation. The pathogen appeared very active with high number of mitochondria, endoplasmic reticulum cisternae, ribosomes, lipid bodies and small vacuoles (Figures 1D-F). In contrast, the beta-cinnamomin silenced strain (FATSS) appeared as a weak aggressive pathogen. Only scarce hyphae were found on the roots (Figures 2A, 2B), showing signs of membrane degradation (Figure 2D), failing root infection in $95 \%$ of the root sections. Possibly, this results from the inability of the strain to synthesize beta-cinnamomin, required for the pathogen colonization [1]. Quercinin was produced by Phytophthora quercina during the invasion process of Q. robur [2], indicating a role for this group of elicitins in the early stages of colonization in Quercus. In agreement with the previous results obtained with $Q$. suber [1], the present work shows that $P$. cinnamomi strain PA 45 (wild type) colonized the roots of $C$. sativa, contrasting with the betacinnamomin silenced strain FATSS which showed a weak aggressiveness. The results suggest that betacinnamomin acts as an aggressiveness factor in the infection of $C$. sativa by P. cinnamomi.

\section{References}

1. Horta M., Caetano P., Coelho A.C., Medeira C, Maia I., Neves D. and Cravador A., European Journal of Plant Pathology 127: 427-436, 2010

2. Brummer M., Arend M., Fromm J., Schlenzig A. and Osswald W.F., Physiological and Molecular Plant Pathology 61: 109-120, 2002 

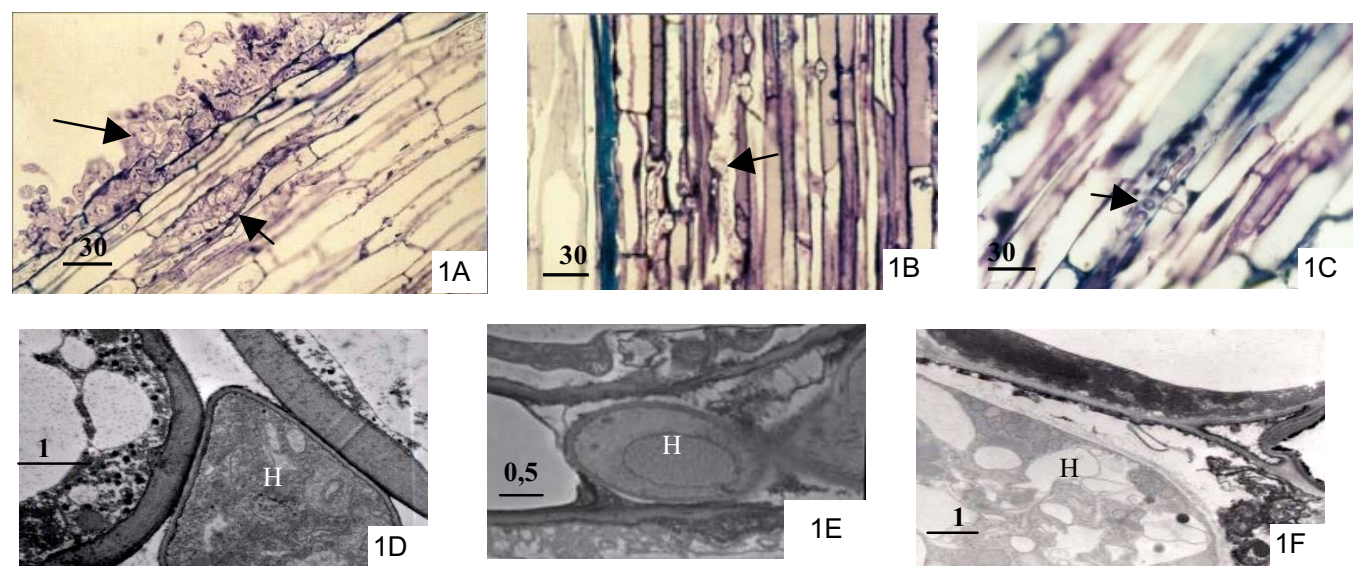

Figure 1. (A to F) - Colonization of the roots of C. sativa by P. cinnamomi strain PA 45 - wild type (arrows). Figs. A to C (LM). A - Heavy colonization of epidermis and cortical parenchyma. B Colonization of phloem vessels. C - Colonization of xylem vessels. Figs. D to F (TEM). D - Host cells of the cortical parenchyma becoming disorganized by an intercellular hypha $(\mathrm{H})$. E and F - Degradation and disruption of cortical cells by intracellular hyphae $(\mathrm{H})$.
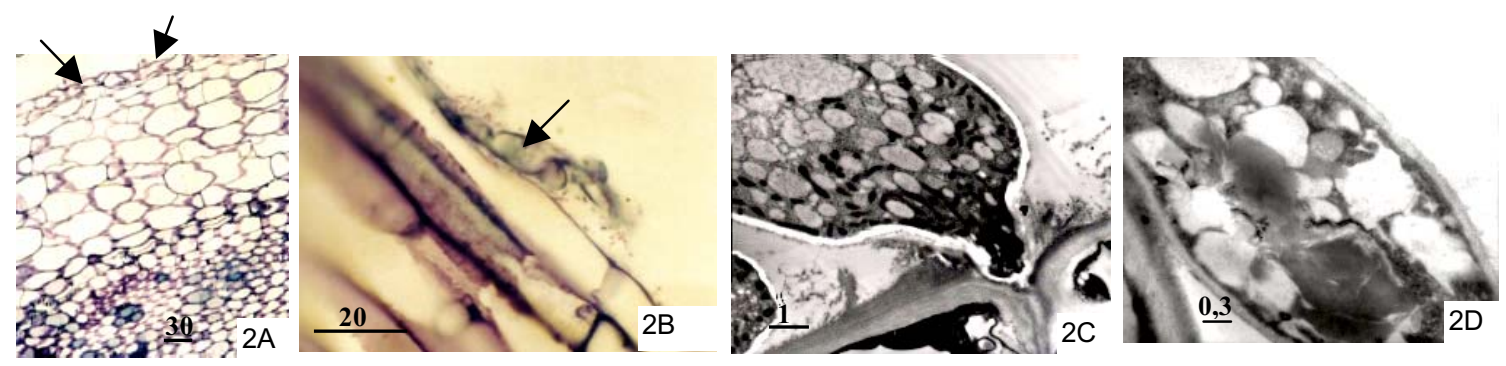

Figure 2. (A to D) - Roots of $C$. sativa inoculated with P. cinnamomi strain FATSS. Figures A to B (LM). A and B - Scarce hyphae (arrows) were visible on epidermal root surface. Root sections free of the pathogen. C and D (TEM) - Hyphae on the epidermis failing the infection. Membrane degradation of $P$. cinnamomi is visible in Fig. D. 